health services gradually stabilised. While the financial capacity of the government is still very limited, the Central Asian region as a whole, and Tajikistan in particular, are the focus of many international donors and non-governmental agencies. As some of them prioritise the social sector and in a few cases mental health, new psychosocial rehabilitation services are being developed and opportunities exist for further improvement of mental healthcare in Tajikistan.

\section{Sources and references}

Central Intelligence Agency. The World Fact Book, Tajikistan. See https:// www.cia.gov/cia/publications/factbook/geos/ti.html (last accessed 23 April 2007).
Médecins Sans Frontières (2003) 'Will You Remember Me?' A Question from the Patients of Psychiatric Institutions in Tajikistan. Report of Médecins Sans Frontières on the Situation in Psychiatric Institutions in the Republic of Tajikistan. Médecins Sans Frontières, Dushanbe, Tajikistan.

National Development Strategy of the Republic of Tajikistan for the Period to 2015, draft, 2006. See http://www.untj.org (last accessed 23 April 2007).

PSFCI (2006) Report on the Assessment of Psychiatric Institutions in the Republic of Tajikistan. PSFCl.

Sanginov, K. \& Romanov, S. (2006) Access to Psychiatric Care in Tajikistan. Tajikistan Bureau on Human Rights.

UN Appeal for Tajikistan (2006) See http://www.untj.org (last accessed 23 April 2007).

UNODC (2002) Regional Conference on Drug Abuse in Central Asia: Situation Assessment and Responses. Conference Report. UNODC.

\title{
Mental health legislation in contemporary India: a critical review
}

\author{
Kunal Kala ${ }^{1}$ and A. K. Kala ${ }^{2}$
}

1Specialist Registrar, Manchester, UK, email kunalkala@hotmail.com ${ }^{2}$ Consultant Psychiatrist, 95-A, Model Gram, Ludhiana 141002, India

\begin{abstract}
fter 20 years of experience with the legislation, it is now a good time to assess the Mental Health Act 1987 of India. How useful has it been to consumers, carers and the mental health profession? It has been perceived as isolationist because it deals only with psychiatric hospitals and excludes a large number of general hospital psychiatric units from its purview. It is also un-implementable in some parts of the country because of the shortage of resources. From a human rights perspective, it is deficient in two important ways: it failed to establish independent review bodies for involuntary admissions; and it lacks provision for research with people who have a mental illness.
\end{abstract}

\section{Historical background}

When Britain granted independence to India in 1947, it left behind a plethora of antiquated laws, including the Indian Lunacy Act of 1912, which used terms originating from that era, such as 'lunatic asylums', 'lunatics' and 'idiot'. Every involuntary admission had to be ordered by a magistrate and every discharge by a board of visitors, which met monthly. After independence, the law was found to be so unworkable that everybody cheerfully bypassed it for the next 40 years while work continued on and off on a new law, until the Mental Health Act 1987 replaced it.

However, implementation of that Act was impeded, both by administrative apathy and by resistance from mental health professionals, who perceived it as having or indeed promoting an isolationist approach to psychiatric patients, who had only recently started receiving the benefits of a resurgent general hospital psychiatry movement in the country (Kala, 1997).

\section{Judicial response to the Erwady trajedy, 2001}

On 7 August 2001, 25 people with a mental illness were burned to death in an accidental fire at night, while chained to pillars in a religious shrine in the Erwady district of Tamil Nadu in South India. These patients had been left by poor families in the care of the shrine management. The Supreme Court of India took 'suo moto' cognisance of the event and started a civil writ petition (no. 334 of 2001), which is still ongoing. The Supreme Court discovered that the regulatory provisions of the Mental Health Act were not being implemented in the country. The Court ordered country-wide implementation of the licensing and other provisions of the Mental Health Act and asked for compliance reports from each of the 34 states. The government complained that the number of mental health professionals in the country was so small that the norms required for licensing a psychiatric hospital, for example one psychiatrist per ten admitted patients, simply could not be met.

The Court then ordered uniform norms of care across both the public and the private sector and asked for a country-wide, state-wise survey to find out the exact number 
of psychiatrists, clinical psychologists, psychiatric social workers, psychiatric nurses and psychiatric beds. There are an estimated 4000 psychiatrists in India, which represents a ratio of approximately one psychiatrist for 250000 people (World Health Organization, 2001). However, this rate varies hugely between urban and rural areas, and between more developed and less developed states. Thus, in some states the ratio falls to one psychiatrist for more than one million people. The majority of psychiatrists work in urban areas and in the private sector. The number of other mental health professionals, such as psychologists and psychiatric nurses, is even lower: there is one nurse for every 10 psychiatrists and one psychologist for every 20. There are an estimated 25000 psychiatric beds in the country, or one bed for every 40000 people (Patel \& Saxena, 2003). About $80 \%$ of these beds are situated in mental hospitals, where the quality of care has been found to violate even basic human rights (National Human Rights Commission, 1999).

The government of India has now unfortunately reduced the minimum standards of care and the norms required by the rules under the Mental Health Act. This 2003 revision submitted by the government to the Supreme Court requires only one psychiatrist and one clinical psychologist or psychiatric social worker for 100 beds and one nurse for 10 beds.

\section{Involuntary admissions}

The 1987 Mental Health Act regulates involuntary admissions mainly through its sections 19 and 20. These stipulate that involuntary admissions can occur only in designated psychiatric hospitals (and not in most general hospital psychiatric units). In addition, involuntary admission requires the recommendation of a psychiatrist and two medical practitioners.

In reality this statutorily required combination of a psychiatric hospital and a psychiatrist and two general practitioners does not exist in vast tracts of India. Thus, the remote hilly state of Arunachal has only one psychiatrist (and no psychiatric hospital). One of the biggest states of India, Madhya Pradesh, has only 30 psychiatrists (for 60 million people). This misfit between the statutory requirement and what is actually possible within the available resources makes the Mental Health Act un-implementable in many parts of the country. As a result, in some areas, treatment and restraint of acutely disturbed unwilling patients are being done in a way which is full of good intentions but which is not technically legal and which is fraught with possibilities of human rights violations.

While the Mental Health Act 1987 lays down that involuntary patients can be admitted only in designated psychiatric hospitals, section $2 \mathrm{q}$ of the Act, which lays down definitions, specifically excludes all psychiatric wards in about 100 government-run general hospitals (most of which are teaching hospitals) from the definition of a 'psychiatric hospital'. This has resulted in a very difficult situation. By virtue of being almost free of cost, these cater to a very large number of patients from middle- and low-income sections of society, who have nowhere else to go for treatment. (A national health payment system by a third party like an insurance company or the government exists only for a small proportion of the population.) The treating clinicians, with the best of intentions but in contravention of the Act, admit the patient on the basis of a 'proxy' consent by a family member. Providing compulsory care thus circumvents the law, reminiscent of the times of the Indian Lunacy Act, when an 'unreasonable' law was similarly bypassed, with everybody keeping quiet because the intention is to provide much-needed care. However, Parliament can easily solve the problem, if it wishes, by deleting a single line from section $2 q$ in a simple amendment.

\section{Tribunal review}

The Mental Health Act 1987 does not provide for a system of review similar to the UK mental health review tribunals. Thus, in cases of perceived wrongful restraint, patients have nowhere to appeal except the mainstream judicial system, which is not sensitive to mental health problems and is anyway clogged with civil and criminal cases. Patients sometimes file a report to the police for wrongful confinement. However, the police similarly are not equipped to understand the nature of psychiatric disorders and can be a cause of considerable harassment to the admitting psychiatrist. This problem could be easily corrected by an add-on amendment to the existing Act, putting in place a review body which 'involuntary' patients can access.

\section{Research}

Section 81(2) of the Act stipulates that research can be done on persons who are mentally ill and unable to give consent, on the basis of consent by a guardian. It is generally accepted that, in India, families play an important and supportive role in the treatment of people with mental illness, and a family member is the right choice for consent for the admission and treatment of patients unwilling to give consent. However, for the purpose of patients participating in research, human rights experts generally favour an independent review body. This is in line with the 'Principles for the Protection of Persons with Mental IIIness and for Improvement of Mental Healthcare' laid down by the General Assembly of the United Nations in 1991. An activist organisation in India has already gone to the Supreme Court with a plea to delete section 81 (2) on this ground (writ petition 562 of 2001).

\section{Other legislation pertaining to mental health}

Section 309 of Indian Penal Code makes attempted suicide a punishable offence and the person liable to be arrested, prosecuted and imprisoned for 1 year. This leads to a situation where all hospitals are legally bound to inform the police whenever a survivor of attempted suicide is brought in, leading to harassment of the patient and the family. Psychiatric help is often not sought because of this. It also results in gross under-reporting of cases of attempted suicide, thus making the available figures unreliable.

Section 377 of Indian Penal Code lays down that homosexual acts, even between consenting adults, are punishable with imprisonment for up to 10 years. This again results in harassment and prevents individuals from 'coming out of 
the closet'. Recently, a High Court rejected a plea to abolish section 377.

On the positive side, the Parliament of India has passed a number of enabling pieces of legislation that have had a direct or indirect effect on the health of its people. These include: the Narcotic Drugs and Psychotropic Substances Act 1985; the Persons with Disabilities Act 1995; the Consumer Protection Act 1986; the Protection of Human Rights Act 1993; the Children Act 1960; and the Juvenile Justice Act 2001 (Khandelwal et al, 2004).

\section{Conclusion}

While in recent years India has enacted many modern, progressive pieces of legislation which have had an indirect effect on the mental health of its people, the main one, the Mental Health Act 1987, has many shortcomings. There have been suggestions from the profession and interested groups on how this can be rectified (Kala, 2004; Sarkar, 2004). The government can invite more suggestions and then submit these to Parliament. However, the problems arising directly out of a shortage of staff will have to wait until the situation improves.

\section{References}

Kala, A. K. (1997) A call for amendment to the licensing provision of the Mental Health Act 1987. Journal of Mental Health and Human Behavior, 2, 101-104.

Kala, A. K. (2004) Why we should opt for a new Mental Health Act and not tinker with the old one. Indian Journal of Psychiatry, 46, 96-98.

Khandelwal, S., Jhingan, H. P., Romesh, S., et al (2004) India: mental health country profile. International Review of Psychiatry, 16, 126-141.

National Human Rights Commission (1999) Quality Assurance in Mental Health. NHRC.

Patel, V. \& Saxena, S. (2003) Psychiatry in India. International Psychiatry, issue 1, July, 16-18.

Sarkar, J. (2004) A new Mental Health Act for India: an ethics based approach. Indian Journal of Psychiatry, 46, 104-114.

World Health Organization (2001) Atlas Country Profiles of Mental Health Resources. WHO. See http://globalatlas.who.int/globalatlas/ predefinedReports/MentalHealth/Files/IN Mental Health Profile.pdf (last accessed 16 April 2007).

\title{
Attention-deficit hyperactivity disorder and use of psychostimulants among children in Turkey
}

\author{
Sahbal Aras ${ }^{1}$ MD and Semih Semin ${ }^{2}$ MD \\ 'Department of Child and Adolescent Psychiatry, Dokuz Eylul University Faculty of Medicine, Inciralti, Izmir, Turkey 35340, \\ emailsahbal.aras@deu.edu.tr \\ ${ }^{2}$ Department of Medical Ethics, Dokuz Eylul University Faculty of Medicine, Inciralti, Izmir, Turkey
}

\begin{abstract}
ecently, the use of psychostimulant medication in children with symptoms of attention-deficit hyperactivity disorder (ADHD) has been subject to extensive debate. The problems faced while assessing and diagnosing ADHD, unnecessary prescribing of psychostimulants, the possible side-effects of psychostimulants on the developing brain, the risk of drug dependency, and the risk of stigmatising children through medicalisation of normal life events are considered among the principal objections to the use of psychostimulant medications. On the other hand, what also need to be taken into account are the increasing evidence on the genetic, biochemical and diagnostic validity of the disorder, the data showing the therapeutic effects of psychostimulants and the rarity of the above-mentioned side-effects, as well as the ethical problems created by insufficient treatment of children because of the concerns of parents. A critical evaluation of these conflicting opinions by mental health professionals might contribute to the application of ethical principles. While making this kind of evaluation, it is important to pay
\end{abstract}

regard to the specific sociocultural features of the country, as well as the prevailing worldwide discussion.

\section{Sociocultural overview of Turkey}

Turkey, a secular state which wants to be a member of the European Union, is at the crossroads of two continents. Twothirds of its population of 70 million live in urban areas and about a quarter live below the poverty limit. According the 2005 'world indicators' of the World Bank, Turkey is 55th among 124 countries with respect to unfair distribution of income (Radikal, 2005).

One-third of the population in Turkey is 15 years of age or younger and the number of students in primary education is 10.5 million. The average class size is about $35-40$, whereas the appropriate number of students in a class is generally considered to be 15-20. Since 1998, the duration of compulsory education has increased from 5 years to 8 years. Nevertheless, $10 \%$ of children $(13 \%$ for 